\title{
microRNA-133b downregulation and inhibition of cell proliferation, migration and invasion by targeting matrix metallopeptidase-9 in renal cell carcinoma
}

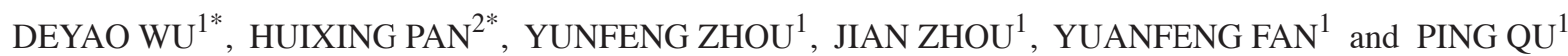 \\ ${ }^{1}$ Department of Urology, The Fourth Affiliated Hospital of Nantong Medical College, Yancheng First People's Hospital, \\ Yancheng, Jiangsu 224001; ${ }^{2}$ Department of Urology, First Affiliated Hospital of Soochow University, \\ Suzhou, Jiangsu 215006, P.R. China
}

Received August 18, 2013; Accepted March 7, 2014

DOI: $10.3892 / \mathrm{mmr} .2014 .2116$

\begin{abstract}
RNA (miRNA)-133b has been revealed to be downregulated in head and neck/oral, bladder, human non-small cell lung, colorectal and esophageal squamous cell cancer. The present study examined the expression of miR-133b in renal cell carcinoma (RCC) cell lines and the effects of miRNA-133b on RCC cell proliferation, migration and invasion. Quantitative polymerase chain reaction was used to detect the expression of miR-133b in RCC cell lines. Following transfection of miR-133b, the expression of miR-133b was examined and a cell viability assay, cell migration assay, cell invasion assay, western blot analysis and luciferase assay were conducted in RCC cell lines. The present study revealed that miRNA-133b was downregulated and inhibited cell proliferation, migration and invasion in 786-O and A498 cells. In addition, to the best of our knowledge, the present study provided the first evidence that miRNA-133b may directly target matrix metallopeptidase 9 (MMP-9) in RCC. The present study also provided evidence that miRNA-133b suppresses cell proliferation, migration and invasion by targeting MMP-9 in RCC cell lines. These results suggested that miRNA-133b may be used for the development of novel molecular markers and therapeutic approaches to inhibit the metastasis of RCC.
\end{abstract}

Correspondence to: $\mathrm{Dr}$ Ping Qu, Department of Urology, The Fourth Affiliated Hospital of Nantong Medical College, Yancheng City First People's Hospital, 15 Yuehe Road, Yancheng, Jiangsu 224001, P.R. China

E-mail: luqiang0405@163.com

*Contributed equally

Key words: renal cell carcinoma, matrix metallopeptidase-9, microRNA-133b

\section{Introduction}

Renal cell carcinoma (RCC) is the most common neoplasm of the kidney in adults, accounting for $\sim 3 \%$ of adult malignancies (1), with a mortality rate of $>40 \%$ (2). Approximately 60,920 novel cases of RCC were diagnosed in the United States in 2011, with an estimated 13,120 mortalities (3). Worldwide, the incidence of RCC is $>200,000$ novel cases per year, with $>100,000$ mortalities annually (4). The most common type of RCC is clear cell RCC (ccRCC), representing $>75-80 \%$ of all RCC cases (5). Almost $25-30 \%$ of patients with RCC exhibit evidence of metastases at initial presentation (6). The resection of the diseased kidney is a standard therapeutic approach for RCC. Although the overall survival rate is $>60 \%$ over 5 years, $\sim 30 \%$ of patients who have a diagnosis of localized RCC develop metastatic recurrence $(7,8)$. Patients with metastatic RCC face a poor prognosis and have limited therapeutic options. The median survival rate in a recent cohort was only 1.5 years with $<10 \%$ of patients surviving to 5 years (4). Thus, novel treatments are required to improve the prognosis for patients with RCC.

RNA can be divided into two categories, protein coding RNA and non-coding RNA (ncRNA). It is important to examine the functions of ncRNAs and their association with human diseases, including cancer (9). microRNAs (miRNAs) are a class of naturally occurring, endogenous small ncRNAs, in the size range of 19-25 $\mathrm{nt}$ (10). They regulate gene expression at the post-transcriptional level by binding through partial sequence homology to the $3^{\prime}$ untranslated region (3'UTR) of mammalian target mRNAs and causing translational inhibition and/or mRNA degradation (11). It has been hypothesized that miRNAs regulate the expression of approximately one third of human genes (12). A growing body of evidence indicates that miRNAs are aberrantly expressed in numerous types of human cancer and they may function as oncogenes and tumor suppressors. Upregulated miRNAs in cancer may function as oncogenes by negatively regulating tumor suppressors. By contrast, downregulated miRNAs may normally function as tumor suppressor genes and inhibit cancer by regulating oncogenes $(13,14)$. Since miRNAs are involved in critical cellular processes, previous studies have demonstrated that they are 
also involved in the pathogenesis of various diseases, including those of the kidney (15).

miR-133 is an miRNA family containing miR-133a and miR-133b (16). miR-133a has also been commonly identified to be downregulated in various types of human malignancy, including RCC, bladder cancer, pancreatic ductal adenocarcinoma, osophageal squamous cell carcinoma of the tongue, hepatocellular and lung carcinomas. However, the functions of miR-133b have yet to be investigated in RCC. The present study demonstrated that miR-133b was able to inhibit RCC cell proliferation, migration and invasion by the downregulation of matrix metallopeptidase 9 (MMP-9). These results aid our understanding of the mechanisms underlying metastasis and may lead to the identification of novel targets that may be used for the development of molecular markers and therapeutic approaches to inhibit the metastasis of RCC.

\section{Materials and methods}

Cells and culture conditions. The 786-O and A498 human clear cell RCC (ccRCC)-derived cell lines were obtained from the Shanghai Institute of Cell Biology, Chinese Academy of Sciences (Shanghai, China). The cells were incubated in RPMI-1640 (Hyclone, South Logan, UT, USA) or Dulbecco's modified Eagle's medium (DMEM; Gibco-BRL, Carlsbad, CA, USA) supplemented with $10 \%$ heat-inactivated fetal calf serum, $100 \mathrm{U} / \mathrm{ml}$ penicillin and $100 \mathrm{mg} / 1$ streptomycin at $37^{\circ} \mathrm{C}$ in a humidified atmosphere containing $5 \% \mathrm{CO}_{2}$.

RNA extraction and quantitative polymerase chain reaction $(q P C R)$. Total RNA was extracted from cells and the normal kidney samples using TRIzol reagent (Invitrogen Life Technologies, Carlsbad, CA, USA) according to the manufacturer's instructions. The primers used were as follows: GAPDH, 5'-GAAATCCCATCACCATCTTCCAGG-3'; miR-133b, 5'-TTGGTCCCCTTCAACCAGCTGT-3'. qPCR for miR-133b was performed with TaqMan microRNA assay kits (Applied Biosystems, Foster City, CA, USA) according to the manufacturer's instructions. qPCR was performed on an AB7300 thermal cycler (Applied Biosystems) using an miR-133b primer set and the double strand binding dye SYBR Green (Applied Biosystems). GAPDH was used as an internal control. Every sample was replicated three times. The data were analyzed by comparing $\mathrm{Ct}$ values.

Transfection of the miR-133b mimic, and NC and luciferase reporter plasmids. The mature miR-133b mimic, scrambled control (NC) and luciferase reporter plasmids were designed and synthesized by GenePharma (Shanghai, China). The sequence of the miR-133b mimic was 5'-UUUGGUCCCCUUCAACCAGCUA-3'. The sequence of the NC mimic was 5'-UUCUCCGAACGUGUCACGUTT-3'. The insertion fragment was confirmed by DNA sequencing. Cell transfection and cotransfection were performed using Lipofectamine 2000 (Invitrogen Life Technologies) according to the manufacturer's instructions.

Cell viability assay. Cell proliferation was determined by the MTT assay. The cells transfected with the miR-133b mimic or the NC were seeded in 96-well plates at a density of 3,000 cells per well. Cell proliferation was documented every $24 \mathrm{~h}$ for five days following the manufacturer's instructions. Briefly, MTT solution was added into each well and incubated at $37^{\circ} \mathrm{C}$ for $4 \mathrm{~h}$. The plates were spun (200 x g, $\left.10 \mathrm{~min}\right)$ and the purple colored precipitates of formazan were dissolved in $200 \mu \mathrm{l}$ dimethylsulfoxide. The absorbance was measured at $490 \mathrm{~nm}$ using an automatic multi-well spectrophotometer (Bio-Rad, Richmond, CA, USA). There were 6-wells replicated for every time point in each group. The suppression rate was calculated using the formula: Suppression rate $=\left(1-\mathrm{OD}_{\text {miR-133b }} / \mathrm{OD}_{\text {miR-NC }}\right) \times 100$, where OD is the optical density. All the experiments were performed in triplicate.

Cell migration and invasion assay. Cell motility was measured using $8 \mu \mathrm{m}$-pore polycarbonate membrane Boyden chambers inserted into a transwell apparatus (Costar, Cambridge, MA, USA). The transfected cells (miR-133b mimics and NC) growing in the log phase were treated with trypsin/EDTA solution, washed once with serum-containing RPMI-1640 medium, centrifuged (200 x g, $10 \mathrm{~min}$ ), and re-suspended as single-cell solutions. A total of $1 \times 10^{5}$ cells in $0.2 \mathrm{ml}$ serum-free RPMI-1640 medium were seeded onto transwell apparatus. RPMI-1640 (600 $\mu \mathrm{l})$ containing $20 \%$ fetal bovine serum was added to the lower chamber. The invasion assay was performed by the same procedure; however, the filters of the transwell chambers were coated with $30 \mu \mathrm{g}$ Matrigel (BD Biosciences, San Jose, CA, USA). Following incubation for $12-24 \mathrm{~h}$ at $37^{\circ} \mathrm{C}$ in a $5 \% \mathrm{CO}_{2}$ incubator, cells on the top surface of the insert were removed by wiping with a cotton swab. The cells that migrated to the bottom surface of the insert were fixed in $100 \%$ methanol for $2 \mathrm{~min}$, stained in $0.5 \%$ crystal violet for $2 \mathrm{~min}$, rinsed in phosphate-buffered saline and then subjected to microscopic inspection (magnification, x200; BX51WI-DPMC; Olympus, Tokyo, Japan). The values for invasion and migration were obtained by counting five fields per membrane and represent the average of three independent experiments.

Western blot analysis. The primary antibodies used in the present study, including epidermal growth factor receptor (EGFR), MMP-9 and $\beta$-actin, were products of Bioworld Technology (Louis Park, MN, USA). The total protein of cells was prepared using radioimmunoprecipitation assay lysis buffer. The protein concentration in the resulting lysate was determined using the bicinchoninic acid protein assay. Equal quantities of protein were loaded onto a SDS-PAGE and transferred onto a polyvinylidene difluoride membranes (Beyotime Institute of Biotechnology, Shanghai, China). Following inhibition with 5\% degreased milk in Tris-buffered saline with $0.1 \%$ Tween-20 (TBST), the membranes were incubated overnight with the appropriate primary antibody. Next, they were washed and incubated with the corresponding horseradish peroxidase-conjugated secondary antibody at 1:1,000 dilution in TBST. The blot was developed with enhanced chemiluminescence solution (Pierce Biotechnology, Inc., Rockford, IL, USA) and images were captured by a FluorChem imaging system (Alpha Innotech, San Leandro, CA, USA). The intensity of each spot was read and analyzed using AlphaEaseFC software (Alpha Innotech, San Leandro, CA, USA). $\beta$-actin served as a loading control. 
$\mathbf{A}$

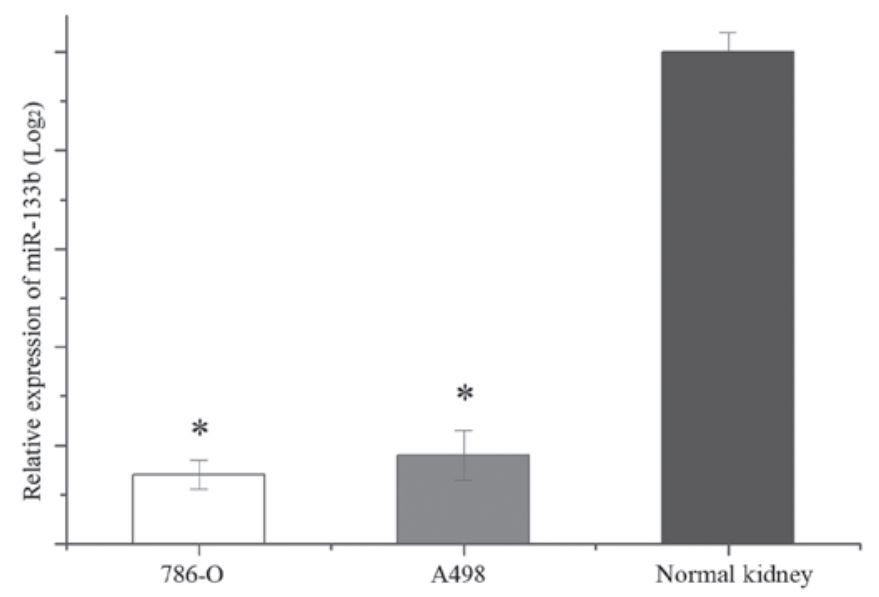

B
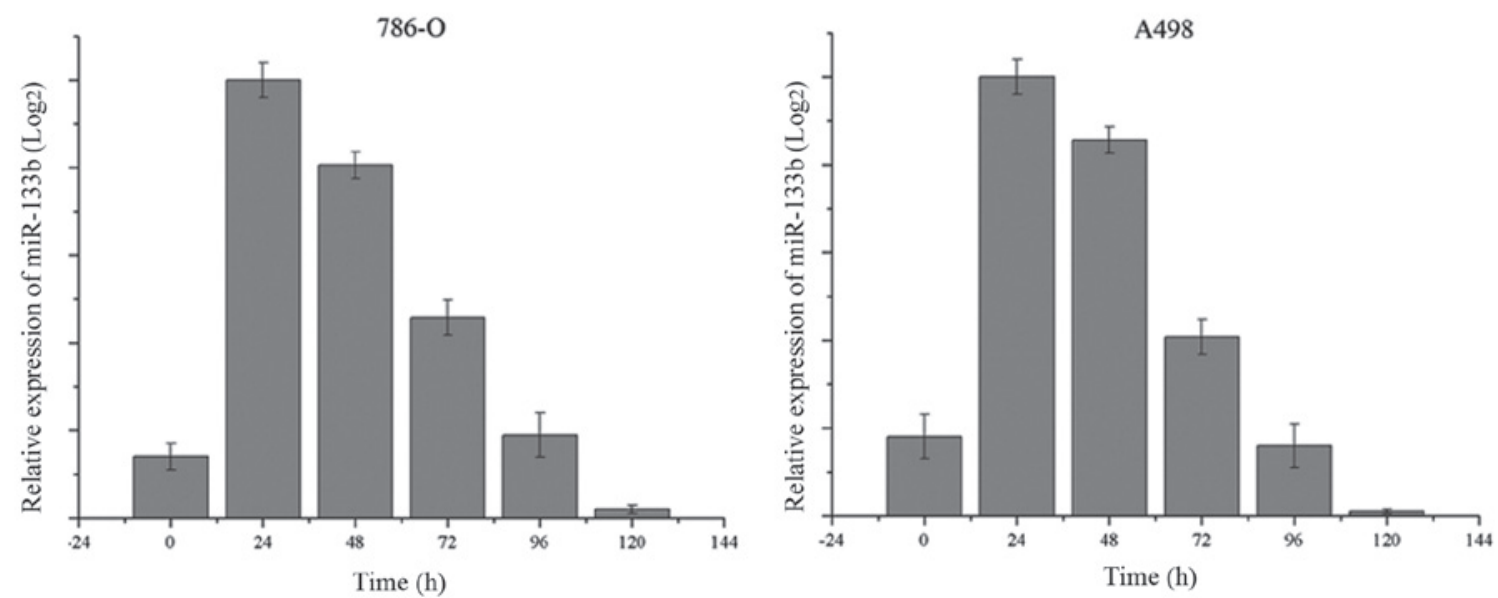

Figure 1. (A) miR-133b was significantly downregulated in 786-O and A498 cells in comparison with normal kidney RNA (*P<0.05). (B) Expression of miR-133b following transfection of miR-133b in 786-O and A498 cells. Following transfection of miR-133b, the expression level was markedly increased until $\sim 120 \mathrm{~h}$ in $786-\mathrm{O}$ and A498 cells. miR-133b, microRNA-133b.

Luciferase assay. TargetScan 5.2 (http://www.targetscan.org/) and PicTar (http://pictar.mdc-berlin.de/) were used to assess the complementarity of miR-133b to the MMP-9 3'-UTR. Otherwise, luciferase reporter assays were performed to evaluate whether MMP-9 is a bona fide target of miR-133b. The cells were plated in a 12-well plate at $~ 90 \%$ confluence and transfected with $0.5 \mu \mathrm{g}$ of reporter plasmid, $40 \mathrm{nmol} \mathrm{miR-133b}$ mimic or their negative control by Lipofectamine 2000. Each sample was also cotransfected with $0.05 \mu \mathrm{g}$ pRL-CMV plasmid expressing Renilla luciferase (Promega Corporation, Madison, WI, USA) as an internal control for transfection efficiency. Following transfection (48 h), cells were harvested with passive lysis buffer, a component of the Dual-Luciferase Reporter Assay system (Tecan, Theale, UK), according to the manufacturer's instructions. An appropriate volume of cell lysate was added to a well of the F96 microwell plates, followed by $25 \mu 1$ LARII. Firefly luciferase and Renilla luciferase activity was measured with a luminometer (Tecan, Theale, UK). Firefly luciferase activity was normalized to Renilla luciferase activity for each transfected well. Each assay was replicated three times.

Statistical analysis. Data are presented as the mean \pm standard deviation, and compared using Student's t-test in Stata 10.0
(College Station, TX, USA). Double-tailed $\mathrm{P}<0.05$ was considered to indicate a statistically significant difference.

\section{Results}

Expression levels of miR-133b prior to and following the transfection of miR-133b into RCC cell lines. Firstly, the endogenous levels of miR-133b in 786-O and A498 cells were examined. As shown in Fig. 1A, miR-133b was significantly downregulated in 786-O and A498 RCC cell lines, in comparison with normal kidney RNA $(\mathrm{P}<0.05)$. Following transfection of miR-133b, the levels of miR-133b were detected every 24 h. As shown in Fig. 1B, the expression level was markedly increased until $\sim 120 \mathrm{~h}$ in $786-\mathrm{O}$ and A498 cells. The level of miR-133b following the transfection of miR-133b also gradually decreased (shown in Fig. 1B).

miR-133b suppresses cell proliferation in RCC cell lines. To measure the effect of miR-133b on cell proliferation, an MTT assay was used. As expected, the upregulation of miR-133b significantly inhibited cell proliferation (Fig. 2). MTT assays revealed that following $144 \mathrm{~h}$ of treatment, the suppression rate of miR-133b reached $23.42 \pm 3.2 \%$ in 786 - $\mathrm{O}$ cells and 
A

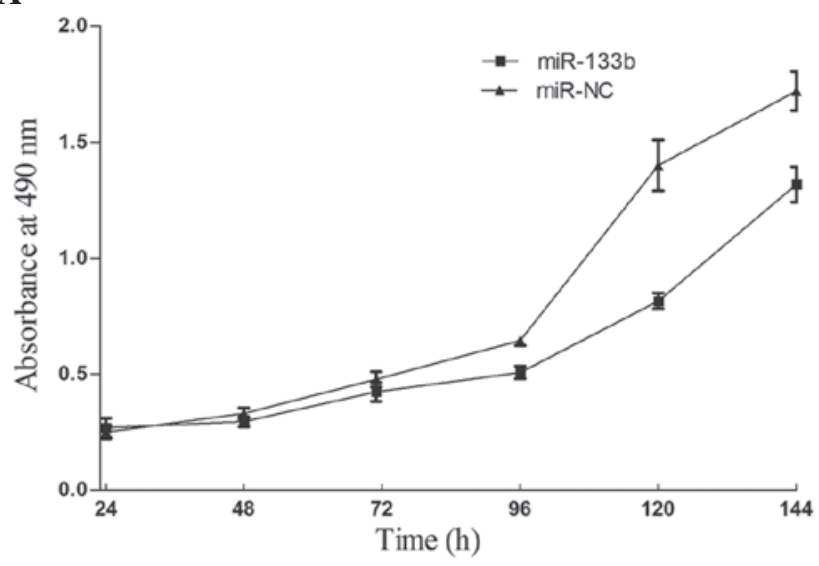

B

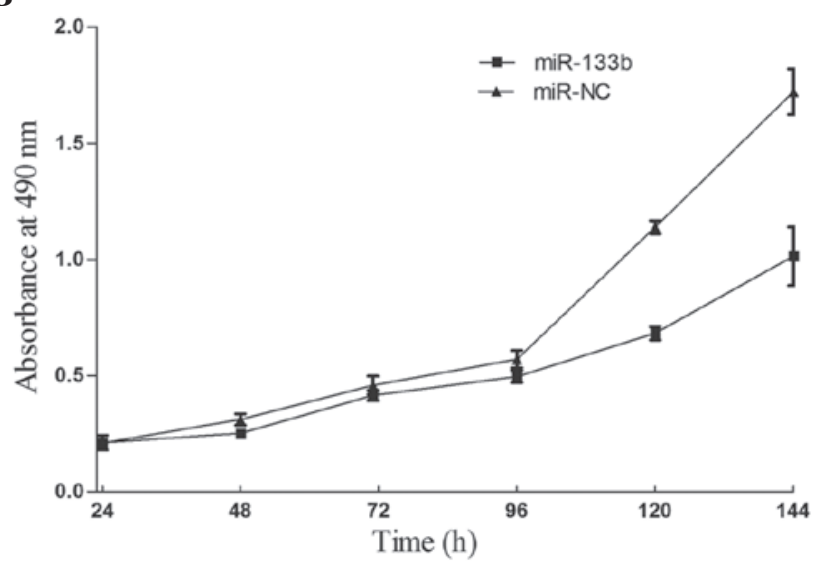

Figure 2. (A) Viability of 786-O cells following transfection of miR-133b. Cell proliferation was determined by the MTT assay. The results indicated that upregulation of miR-133b significantly suppressed cell proliferation. (B) Viability of A498 cells following transfection of miR-133b. The cell proliferation was determined by the MTT assay. The results indicated that upregulation of miR-133b significantly suppressed cell proliferation. miR-133b, microRNA-133b.

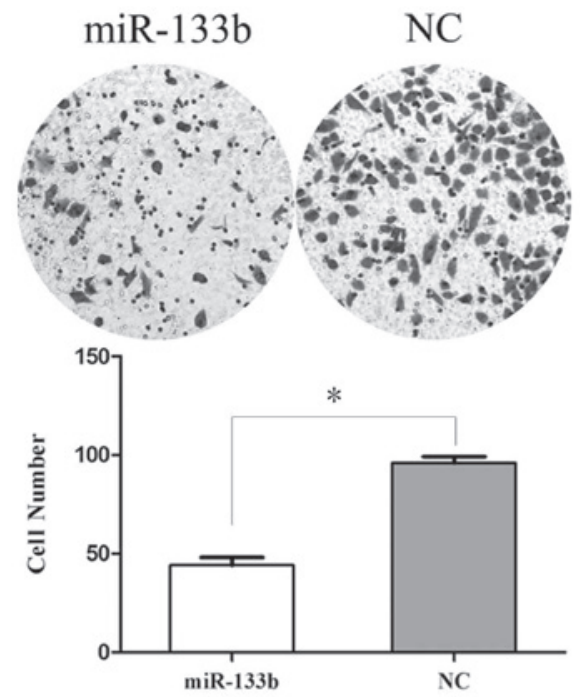

786-O migration

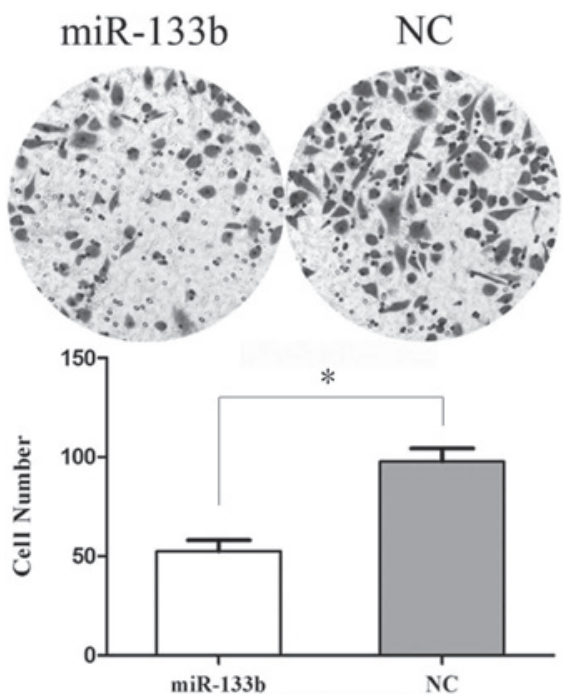

A498 migration

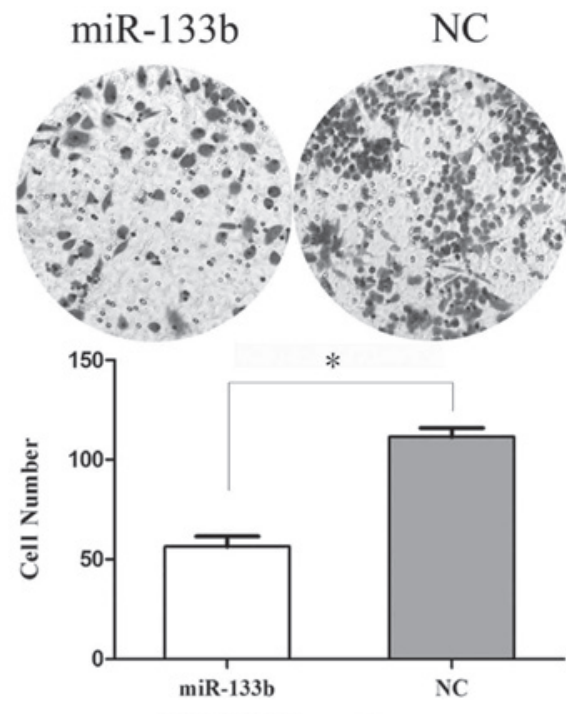

786-O invasion

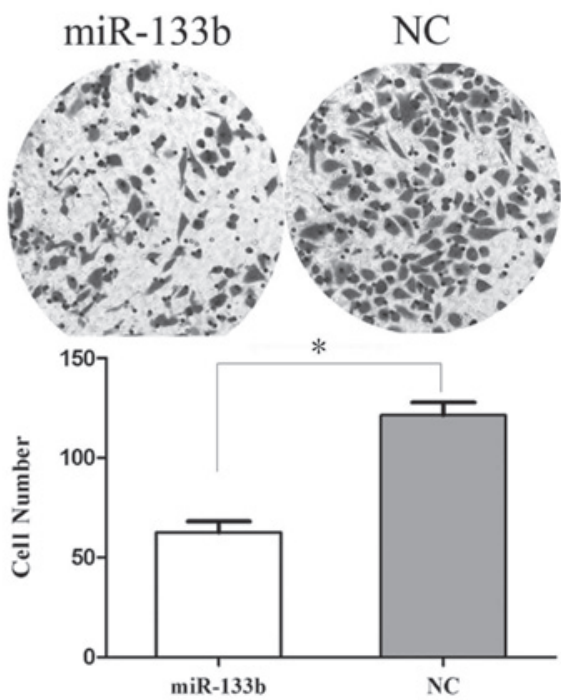

A498 invasion

Figure 3. miR-133b inhibited cell migration and invasion. Following $12 \mathrm{~h}$ of incubation, cell migration was significantly decreased in miR-133b groups compared with in the control group. Following $24 \mathrm{~h}$ of incubation, miR-133b transfected cells demonstrated significantly decreased invasiveness compared with the control cells ( $\mathrm{P}<0.05)$. miR-133b, microRNA-133b; NC, scrambled control. 

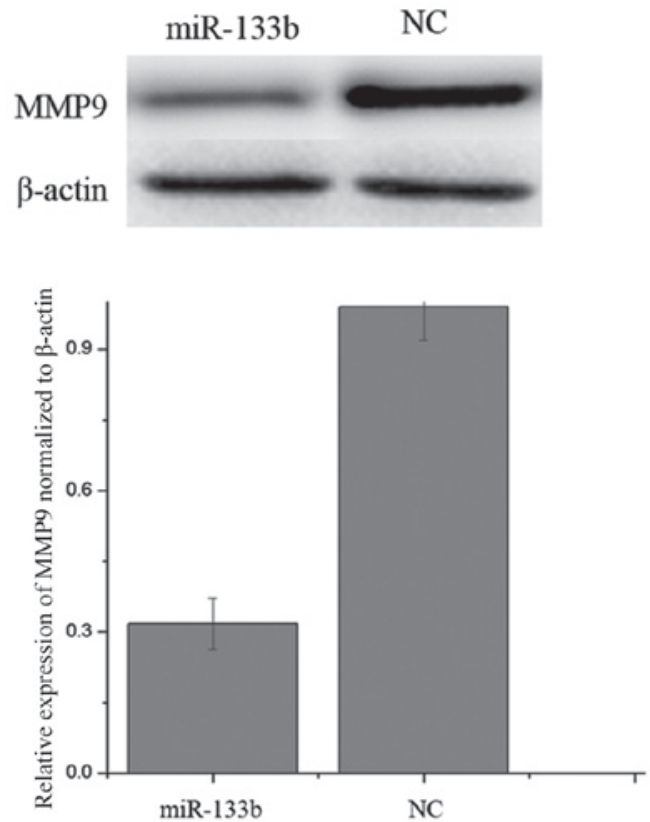
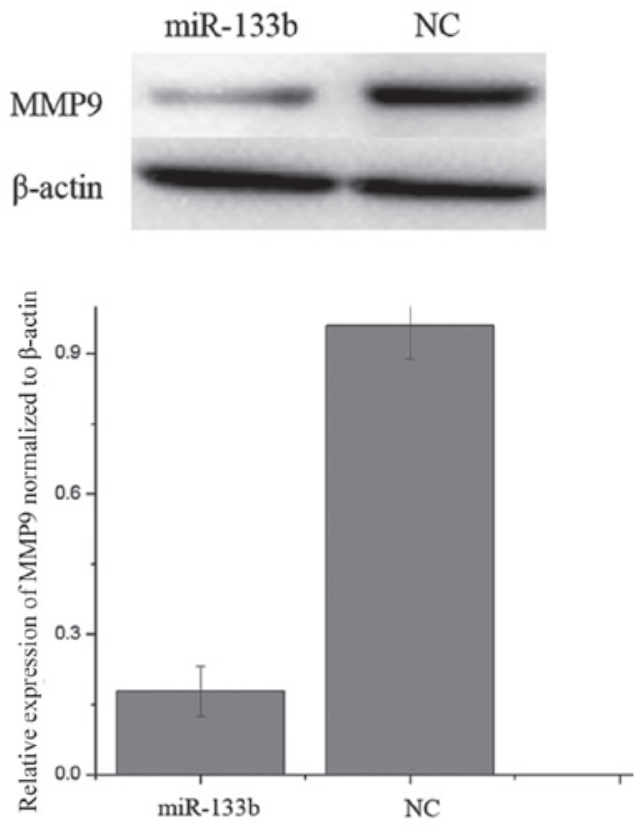

Figure 4. MMP-9 was significantly decreased in 786-O and A498 cells following transfection of miR-133b. miR-133b, microRNA-133b; NC, scrambled control; MMP-9, matrix metallopeptidase 9.

$35.71 \pm 4.5 \%$ in A498 cells. The results indicated that miR133 b may be important in 786-O and A498 cells.

miR-133b inhibits cell migration and invasion in RCC cell lines. To measure the effect of miR-133b on tumor cell migration, the transwell apparatus assay was used (Fig. 3). The transfected cells (miR-133b mimics and NC mimics) growing in the log phase were collected and cultured on transwell apparatus. Following $12 \mathrm{~h}$ of incubation, cell migration was significantly decreased in miR-133b groups compared with the control group $(\mathrm{P}<0.05)$. Using transwell apparatus pre-coated with Matrigel, the effects of miR-133b on cell invasiveness were examined. Following $24 \mathrm{~h}$ of incubation, miR-133b transfected cells demonstrated significantly decreased invasiveness compared with the control cells $(\mathrm{P}<0.05)$. These results indicated that miR-133b inhibits cell migration and invasion in RCC cell lines.

miR-133b suppresses the expression of MMP-9 in RCC cell lines. In bioinformatics studies, MMP-9 was identified as a putative target of miR-133b. Western blot analysis was performed to examine whether the MMP-9 protein level was decreased following ectopic overexpression of miR-133b. As shown in Fig. 4, MMP-9 was significantly decreased in 786-O and A498 cell lines $72 \mathrm{~h}$ after transfection of miR133b. Thus, miR-133b reduces the protein level of MMP-9 in RCC cells.

EGFR and MMP-9 are direct targets of miR-133b. To determine whether miR-133b targets the 3'UTR of MMP-9, TargetScan 5.2 and PICTAR were used to assess the complementarity of miR-133b to the MMP-9 3'UTR. It was demonstrated that MMP-9 mRNA contained a miR-133b seven-nucleotide seed match at position 43-49 of the MMP-9 3'UTR (shown in Fig. 5A).
Luciferase reporter assays were performed to evaluate whether the site was able to directly mediate expression inhibition. As shown in Fig. 5B, the overexpression of miR-133b was able to suppress MMP-9 3'UTR-luciferase activity by $39 \%$ in $786-\mathrm{O}$ cells and $51 \%$ in A498 cells $(\mathrm{P}<0.05)$. Thus, MMP-9 may be a direct target of miR-133b in vitro.

\section{Discussion}

miR-133 is an miRNA family containing miR-133a and miR-133b. miR-133a is a multicopy gene with two copies distributed on chromosome 18 and chromosome 20, which neighbor miR-1, another muscle enriched miRNA, while miR$133 \mathrm{~b}$ is located on chromosome 6 and marginally different in base sequence from that of miR-133a (16). miR-133a has been revealed to be downregulated in several types of human cancer, including RCC (17), esophageal squamous cell carcinoma (18), bladder cancer (19), ileal carcinoid cancer (20) and rhabdomyosarcoma (21). miR-133b is expressed in T cells and has been revealed to be downregulated in head and neck/oral, bladder, human non-small cell lung, colorectal and esophageal squamous cell cancer (22).

Identification of miR-133b target genes is critical for understanding its role in tumorigenesis and is important for defining novel therapeutic targets. miR-133a has been identified to regulate oncogenic transcripts in human cells, including fascin actin-bundling protein 1 (FSCN1), LIM and SH3 protein 1, glutathione S-transferase pi gene and transgelin $2(23,24)$, however, miR-133b targets FSCN1, Bcl-2-like protein 2, c-MET and EGFR (16,22). Therefore, upregulating miR-133a/b or providing analogous pharmaceutical compounds exogenously, may be effective cancer therapies for tumors resulting from the activation or overexpression of these oncogenes. The present study demonstrated that miR-133b was downregulated in RCC cell lines and reduced cell migration 
A

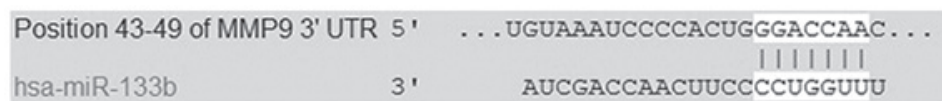

B
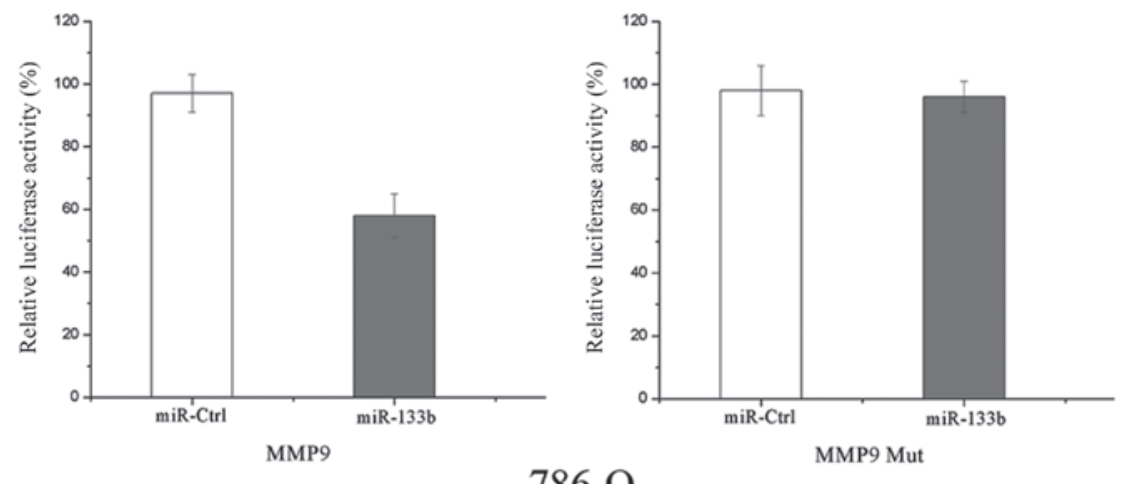

$786-\mathrm{O}$
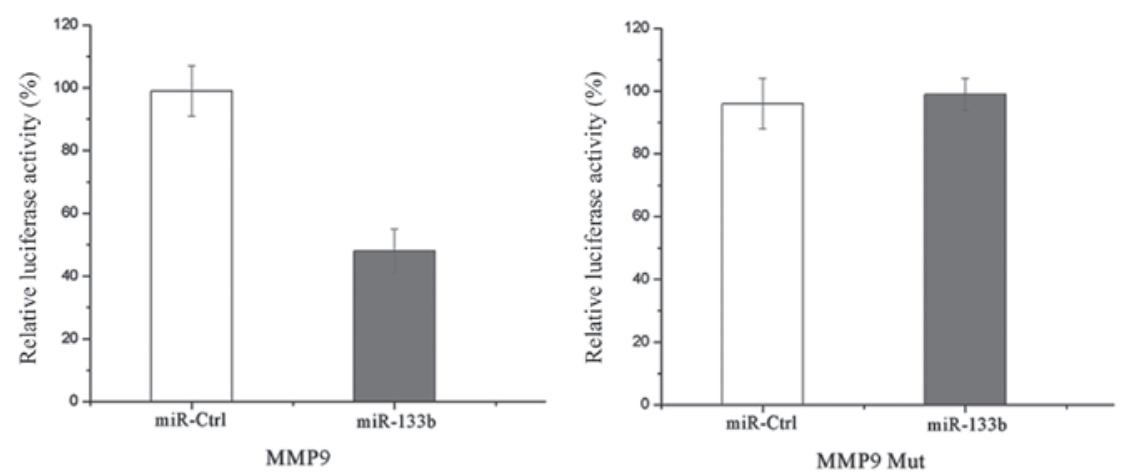

A498

Figure 5. (A) TargetScan showed that MMP-9 mRNA contained a miR-133b seven-nucleotide seed match at position 43-49 of the MMP-9 3'UTR. (B) MMP-9 may be a direct target of miR-133b in vitro. Luciferase activity was significantly decreased when cotransfected with miR-133b and the reporter plasmid in 786-O and A498 cells. Overexpression of miR-133b was able to suppress MMP-9 3'UTR-luciferase activity by $39 \%$ in $786-\mathrm{O}$ cells and $51 \%$ in A498 cells miR-133b, microRNA-133b; MMP-9, matrix metallopeptidase 9; 3'UTR, 3' untranslated region.

and invasion by downregulating the expression of MMP-9. Our findings suggested that miR-133b was able to be used for the development of novel molecular markers and therapeutic approaches to inhibit the metastasis of RCC.

Proteolytic degradation of the extracellular matrix (ECM) is a fundamental aspect of cancer development and a key event in the regulation of tumor proliferation and metastasis. MMPs are a family of zinc-dependent endopeptidases that are collectively capable of degrading the majority of the components of the basement membrane and ECM, facilitating cell migration (25). They are crucial in certain non-malignant and malignant pathologies, including rheumatoid arthritis, aortic aneurysms, myocardial infarctions, septic shock, liver disease, tumor invasion and neoplastic metastasis (26). Therefore, elevated levels of MMPs have been detected in the serum and urine of patients with numerous different types of cancer, including cancer of the bladder, breast, lung, colon, head and neck as well as melanoma (27). In view of their importance in tumor invasion and metastasis, inhibitors of MMP activity have been investigated as a method of preventing/decreasing tumor spread. Several pharmaceutical companies are currently developing low molecular weight MMP inhibitors for clinical use (25). Clinical trials involving batimastat, a potent broad based inhibitor of MMPs 1, 2, 3 and 9 and marimastat (28), and a second-generation water-soluble synthetic MMP inhibitor, have been evaluated in patients with pancreatic, pulmonary, ovarian and mammary carcinomas.

There are 24 soluble and membrane-anchored members of the MMP family, which can be divided into four families based on structure and substrate specificity: Collagenases, gelatinases, stromelysins and membrane-associated MMPs. Among the previously reported human MMPs, MMP-2 and MMP-9 are key enzymes that degrade type IV collagen (29). MMP-9, a $92 \mathrm{kDa}$ type IV collagenase, is regulated through formation of proenzyme complexes with endogenous TIMP-1. The spatial expression of MMP-9 in the kidney is complex and species specific (30). MMP-9 is mainly expressed in collecting duct cells and to a lesser extent in proximal tubule and podocytes of mice (31), in the proximal and distal tubules of monkeys (32), and in glomerular mesangial cells of humans (33). The regulated expression of MMP-9 has been implicated in renal development, macrophage differentiation, atherosclerosis, inflammation, rheumatoid arthritis and tumor invasion (34,35). The mechanisms of MMP-9 gene activation in human cancer cells are not well defined. The production of MMP-9 may be induced by a number of factors, including the inflammatory cytokine tumor necrosis 
factor $(36,37)$. In RCC, Kugler et al revealed that MMP-9 had a strong correlation between increased gene expression and tumor stage and aggressiveness (38). Lein et al measured MMP-9 using an ELISA technique in 36 patients with RCC and revealed that plasma MMP-9 concentrations were significantly higher in patients with RCC compared with in healthy controls with a sensitivity of only $36 \%$ in detecting RCC. In addition, no correlation with tumor type, grade or stage was identified (39). Kallakury demonstrated that the increased expression of MMP-9 in RCC correlated with poor prognostic variables, including shortened patient survival time (25). It suggested that MMP-9 may serve as a marker for transformation and invasion in RCC, or serve as a target for cancer therapy in order to inhibit the metastasis of RCC. The results of the present study suggested that miR-133b suppressed the migration and invasion of RCC cells through the downregulation of MMP-9. It may be investigated as a predictive value for early detection of tumor metastasis and for targeted therapeutic drugs to inhibit RCC invasiveness.

In conclusion, to the best of our knowledge, this is the first study to demonstrate that miR-133b was downregulated in RCC cell lines, and inhibited RCC cell migration and invasion by the downregulation of MMP-9 expression. These findings have therapeutic implications and may be exploited for the further treatment of RCC.

Future studies are required to address whether the potential of miR-133b may be fully realized in cancer treatment. If so, it may be beneficial for the treatment of RCC.

\section{References}

1. White NM and Yousef GM: MicroRNAs: exploring a new dimension in the pathogenesis of kidney cancer. BMC Med 8: $65,2010$.

2. van Spronsen DJ, de Weijer KJ, Mulders PF and De Mulder PH: Novel treatment strategies in clear-cell metastatic renal cell carcinoma. Anticancer Drugs 16: 709-717, 2005.

3. Siegel R, Ward E, Brawley O and Jemal A: Cancer statistics, 2011: the impact of eliminating socioeconomic and racial disparities on premature cancer deaths. CA Cancer J Clin 61: 212-236, 2011.

4. Xue YJ, Xiao RH, Long DZ, Zou XF, Wang XN, Zhang GX, Yuan YH, Wu GQ, Yang J, Wu YT, et al: Overexpression of FoxM1 is associated with tumor progression in patients with clear cell renal cell carcinoma. J Transl Med 10: 200, 2012.

5. Yan BC, Mackinnon AC and Al-Ahmadie HA: Recent developments in the pathology of renal tumors: morphology and molecular characteristics of select entities. Arch Pathol Lab Med 133: 1026-1032, 2009.

6. Cindolo L, Patard JJ, Chiodini P, Schips L, Ficarra V, Tostain J, de La Taille A, Altieri V, Lobel B, Zigeuner RE, et al: Comparison of predictive accuracy of four prognostic models for nonmetastatic renal cell carcinoma after nephrectomy: a multicenter European study. Cancer 104: 1362-1371, 2005.

7. Jemal A, Siegel R, Ward E, Hao Y, Xu J and Thun MJ: Cancer statistics, 2009. CA Cancer J Clin 59: 225-249, 2009.

8. Zisman A, Pantuck AJ, Wieder J, Chao DH, Dorey F, Said JW, deKernion JB, Figlin RA and Belldegrun AS: Risk group assessment and clinical outcome algorithm to predict the natural history of patients with surgically resected renal cell carcinoma. J Clin Oncol 20: 4559-4566, 2002.

9. Hidaka H, Seki N, Yoshino H, Yamasaki T, Yamada Y, Nohata N, Fuse M, Nakagawa M and Enokida H: Tumor suppressive microRNA-1285 regulates novel molecular targets: aberrant expression and functional significance in renal cell carcinoma. Oncotarget 3: 44-57, 2012.

10. Pampalakis G, Diamandis EP, Katsaros D and Sotiropoulou G: Down-regulation of dicer expression in ovarian cancer tissues. Clin Biochem 43: 324-327, 2010.
11. Garzon R, Pichiorri F, Palumbo T, Visentini M, Aqeilan $\mathrm{R}$, Cimmino A, Wang H, Sun H, Volinia S, Alder $\mathrm{H}$, et al: MicroRNA gene expression during retinoic acid-induced differentiation of human acute promyelocytic leukemia. Oncogene 26: 4148-4157, 2007.

12. Schickel R, Boyerinas B, Park SM and Peter ME: MicroRNAs: key players in the immune system, differentiation, tumorigenesis and cell death. Oncogene 27: 5959-5974, 2008.

13. Esquela-Kerscher A and Slack FJ: Oncomirs - microRNAs with a role in cancer. Nat Rev Cancer 6: 259-269, 2006.

14. Calin GA and Croce CM: MicroRNA signatures in human cancers. Nat Rev Cancer 6: 857-866, 2006.

15. Zaman MS, Shahryari V, Deng G, Thamminana S, Saini S, Majid S, Chang I, Hirata H, Ueno K, Yamamura S, et al: Up-regulation of microRNA-21 correlates with lower kidney cancer survival. PLoS One 7: e31060, 2012.

16. Tao J, Wu D, Xu B, Qian W, Li P, Lu Q, Yin C and Zhang W: microRNA-133 inhibits cell proliferation, migration and invasion in prostate cancer cells by targeting the epidermal growth factor receptor. Oncol Rep 27: 1967-1975, 2012.

17. Kawakami K, Enokida H, Chiyomaru T, Tatarano S, Yoshino H, Kagara I, Gotanda T, Tachiwada T, Nishiyama K, Nohata $\mathrm{N}$, et al: The functional significance of miR-1 and miR-133a in renal cell carcinoma. Eur J Cancer 48: 827-836, 2012.

18. Kano M, Seki N, Kikkawa N, Fujimura L, Hoshino I, Akutsu Y, Chiyomaru T, Enokida H, Nakagawa $\mathrm{M}$ and Matsubara $\mathrm{H}$ : miR-145, miR-133a and miR-133b: tumor-suppressive miRNAs target FSCN1 in esophageal squamous cell carcinoma. Int J Cancer 127: 2804-2814, 2010.

19. Chiyomaru T, Enokida H, Tatarano S, Kawahara K, Uchida Y, Nishiyama K, Fujimura L, Kikkawa N, Seki N and Nakagawa M: miR-145 and miR-133a function as tumour suppressors and directly regulate FSCN1 expression in bladder cancer. Br J Cancer 102: 883-891, 2010.

20. Ruebel K, Leontovich AA, Stilling GA, Zhang S, Righi A, Jin L and Lloyd RV: MicroRNA expression in ileal carcinoid tumors: downregulation of microRNA-133a with tumor progression. Mod Pathol 23: 367-375, 2010.

21. Rao PK, Missiaglia E, Shields L, Hyde G, Yuan B, Shepherd CJ, Shipley J and Lodish HF: Distinct roles for miR-1 and miR-133a in the proliferation and differentiation of rhabdomyosarcoma cells. FASEB J 24: 3427-3437, 2010.

22. Patron JP, Fendler A, Bild M, Jung U, Müller H, Arntzen MØ, Piso C, Stephan C, Thiede B, Mollenkopf HJ, et al: MiR-133b targets antiapoptotic genes and enhances death receptorinduced apoptosis. PLoS One 7: e35345, 2012.

23. Uchida Y, Chiyomaru T, Enokida H, Kawakami K, Tatarano S, Kawahara K, Nishiyama K, Seki N and Nakagawa M: MiR-133a induces apoptosis through direct regulation of GSTP1 in bladder cancer cell lines. Urol Oncol 31: 115-123, 2013.

24. Chiyomaru T, Enokida H, Kawakami K, Tatarano S, Uchida Y, Kawahara K, Nishiyama K, Seki N and Nakagawa M: Functional role of LASP1 in cell viability and its regulation by microRNAs in bladder cancer. Urol Oncol 30: 434-443, 2012.

25. Kallakury BV, Karikehalli S, Haholu A, Sheehan CE, Azumi $\mathrm{N}$ and Ross JS: Increased expression of matrix metalloproteinases 2 and 9 and tissue inhibitors of metalloproteinases 1 and 2 correlate with poor prognostic variables in renal cell carcinoma. Clin Cancer Res 7: 3113-3119, 2001

26. Morgia G, Falsaperla M, Malaponte G, Madonia M, Indelicato M, Travali S and Mazzarino MC: Matrix metalloproteinases as diagnostic (MMP-13) and prognostic (MMP-2, MMP9) markers of prostate cancer. Urol Res 33: 44-50, 2005.

27. Moses MA, Wiederschain D, Loughlin KR, Zurakowski D, Lamb CC and Freeman MR: Increased incidence of matrix metalloproteinases in urine of cancer patients. Cancer Res 58: 1395-1399, 1998.

28. Brown PD and Giavazzi R: Matrix metalloproteinase inhibition: a review of anti-tumour activity. Ann Oncol 6: 967-974, 1995.

29. Hong S, Park KK, Magae J, Ando K, Lee TS, Kwon TK, Kwak JY, Kim CH and Chang YC: Ascochlorin inhibits matrix metalloproteinase-9 expression by suppressing activator protein-1-mediated gene expression through the ERK1/2 signaling pathway: inhibitory effects of ascochlorin on the invasion of renal carcinoma cells. J Biol Chem 280: 25202-25209, 2005.

30. Tsai JP, Liou JH, Kao WT, Wang SC, Lian JD and Chang HR: Increased expression of intranuclear matrix metalloproteinase 9 in atrophic renal tubules is associated with renal fibrosis. PLoS One 7: e48164, 2012. 
31. Legallicier B, Trugnan G, Murphy G, Lelongt B and Ronco P Expression of the type IV collagenase system during mouse kidney development and tubule segmentation. J Am Soc Nephrol 12: 2358-2369, 2001.

32. Ogbureke KU and Fisher LW: Renal expression of SIBLING proteins and their partner matrix metalloproteinases (MMPs). Kidney Int 68: 155-166, 2005.

33. Catania JM, Chen G and Parrish AR: Role of matrix metalloproteinases in renal pathophysiologies. Am J Physiol Renal Physiol 292: F905-F911, 2007.

34. Stetler-Stevenson WG, Hewitt R and Corcoran M: Matrix metalloproteinases and tumor invasion: from correlation and causality to the clinic. Semin Cancer Biol 7: 147-154, 1996.

35. Nabeshima K, Inoue T, Shimao Y and Sameshima T: Matrix metalloproteinases in tumor invasion: role for cell migration. Pathol Int 52: 255-264, 2002.
36. Zucker S, Lysik RM, Zarrabi MH and Moll U: M(r) 92,000 type IV collagenase is increased in plasma of patients with colon cancer and breast cancer. Cancer Res 53: 140-146, 1993.

37. Lakka SS, Gondi CS, Yanamandra N, Dinh DH, Olivero WC, Gujrati M and Rao JS: Synergistic down-regulation of urokinase plasminogen activator receptor and matrix metalloproteinase-9 in SNB19 glioblastoma cells efficiently inhibits glioma cell invasion, angiogenesis, and tumor growth. Cancer Res 63: 2454-2461, 2003.

38. Kugler A, Hemmerlein B, Thelen P, Kallerhoff M, Radzun HJ and Ringert RH: Expression of metalloproteinase 2 and 9 and their inhibitors in renal cell carcinoma. J Urol 160: 1914-1918, 1998.

39. Lein M, Jung K, Laube C, Hübner T, Winkelmann B, Stephan C, Hauptmann S, Rudolph B, Schnorr D and Loening SA: Matrix-metalloproteinases and their inhibitors in plasma and tumor tissue of patients with renal cell carcinoma. Int J Cancer 85: 801-804, 2000. 